\title{
Role of oxaliplatin combined with 5-fluorouracil and folinic acid in the first- and second-line treatment of advanced colorectal cancer
}

\author{
D. Jonker MD, R.B. Rumble BSc, J. Maroun MD, and the \\ Gastrointestinal Cancer Disease Site Group* of Cancer \\ Care Ontario's Program in Evidence-Based Care
}

\begin{abstract}
\section{Question}

What is the role of oxaliplatin combined with 5-fluorouracil (5-FU) and folinic acid (FA) in the first- and second-line treatment of advanced (unresectable locally advanced or metastatic) colorectal cancer?

\section{Perspectives}

Evidence was selected and reviewed by two members of the Gastrointestinal Cancer Disease Site Group (GI DSG) of Cancer Care Ontario's Program in Evidence-Based Care (PEBC) and by a methodologist. The resulting practice guideline report has been reviewed and approved by the GI DSG, which comprises medical and radiation oncologists, surgeons, a pathologist, and patient representatives.

External review by Ontario practitioners was obtained through a mailed survey. Final approval of the original guideline report was obtained from the Practice Guidelines Coordinating Committee.
\end{abstract}

\section{Outcomes}

Outcomes of interest were 1-year survival, response rates, and quality of life.

\section{Methodology}

The MEDLINE, CANCERLIT, EMBASE, Guidelines International Network, and Cochrane Library databases were

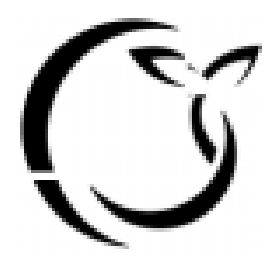

Cancer Care Ontario's Program in Evidence-based Care is sponsored by Cancer Care Ontario and the Ministry of Health and Long-Term Care. systematically searched for relevant studies. Recommendations were formed based on the evidence reviewed. Through a survey, these recommendations were appraised by Ontario clinicians; the recommendations were then revised by the GI DSG. The systematic review and modified recommendations were approved by a review body within PEBC.

\section{Results}

The literature review found twenty-one randomized controlled trials and two meta-analyses. Evidence on first-line treatment found infusional 5-Fu/FA/oxaliplatin (FOLFOX) to be superior to bolus 5-FU/FA/irinotecan (IFL) for rates of median survival and tumour response, with lower incidences of most adverse effects except peripheral neuropathy. For second-line treatment after fluoropyrimidine monotherapy, FOLFOX is a reasonable alternative for patients with contraindications to second-line irinotecan. After progression on infusional 5-FU/FA/irinotecan (FOLFIRI), FOLFOX is the preferred therapy. Evidence from a single randomized trial suggests that additional benefits can be expected with the addition of bevacizumab to the FOLFOX regimen in second-line treatment.

\section{Practice Guideline}

These recommendations apply to adult patients with advanced colorectal cancer who have high performance status (Eastern Cooperative Oncology Group score 0-2).

Refer to Appendix A for available treatment options and to Appendix B for recommended dosages and schedules.

The FOLFOX regimen is an important component of therapy for advanced colorectal cancer.

First-line Therapy In one trial, FOLFOX was shown to be superior to IFL. The FOLFOX regimen has superior rates of median survival and tumour response. Compared with IFL, FOLFOX has lower incidences of severe nausea, vomiting, diarrhea, and febrile neutropenia, but a higher incidence of peripheral neuropathy.

Short-term infusional 5-FU/FA in combination with either oxaliplatin (FOLFOX) or irinotecan (FOLFIRI) are 
both acceptable alternatives for fit patients when combination therapy is the preferred treatment. Choice of first-line therapy may rely on patient factors and preferences - for example, less neuropathy with irinotecan versus less alopecia with oxaliplatin.

Second-line Therapy After progression on first-line anti-thymidylate synthase monotherapy (for example, 5-FU/FA, capecitabine), irinotecan is standard secondline therapy. The FOLFOX regimen is a reasonable alternative for patients with contraindications to the use of second-line irinotecan.

After progression on both irinotecan and an antithymidylate synthase agent, FOLFOX is the preferred therapy. Recent trials suggest that, as compared with FOLFOX alone, FOLFOX combined with bevacizumab provides additional survival benefits.

\section{Qualifying Statements}

The role of radiation therapy, either alone or in combination with chemotherapy, for locally advanced unresectable colorectal cancer is not addressed in this guideline.

Use of chronomodulated regimens is a topic that intersects with the use of oxaliplatin/5-Fu combinations, particularly chronomodulation of 5-Fu in these combinations. Chronomodulation of oxaliplatin has not been extensively studied, and the topic of chronomodulation is beyond the scope of this guideline and is not addressed.

Although data exist to support the use of bevacizumab in combination with FOLFOX in second-line treatment, no first-line treatment data are available on which to make a recommendation.

\section{KEY WORDS}

Oxaliplatin, FOLFOX, bevacizumab, 5-Fu/FA, advanced colorectal cancer

\section{QUESTION}

What is the role of oxaliplatin combined with 5-fluorouracil (5-FU) and folinic acid (FA) in the first- and second-line treatment of advanced (unresectable locally advanced or metastatic) colorectal cancer?

Outcomes of interest were 1-year survival, response rates, and quality of life (QOL).

\section{CHOICE OF TOPIC AND RATIONALE}

In Ontario, Canada, colorectal cancer is the fourth most common cancer site for both sexes combined, representing $13.1 \%$ of all new cancer cases ${ }^{1}$. Colorectal cancer is the third most common site in men $(13.3 \%$ of all new cases) and the second most common site in women $(12.9 \% \text { of all new cases })^{1}$, and it remains the second leading cause of cancer death ( $10.6 \%$ of all cancer deaths) ${ }^{1}$. Considering both men and women, colorectal cancer ranks third as the leading cause of death after breast and lung cancers in females and after lung and prostate cancers in males ${ }^{1}$. For that reason, interest in improving the treatment results for this group of patients is great.

Currently, the standard first-line treatment for metastatic colorectal cancer (MCC) in Canada is a combination of 5-Fu, FA [also known as leucovorin calcium (LV)], and irinotecan - called FOLFIRI - delivered by infusion (Douillard regimen) ${ }^{2}$. Infusional FOLFIRI replaced IFL, which is the same drug combination by bolus delivery. For patients unable to tolerate a combination-therapy regimen, an alternative to FOLFIRI is monotherapy with a first-line thymidylate synthase (TS) inhibitor such as 5-Fu/LV, raltitrexed ${ }^{3}$, or capecitabine, followed by second-line irinotecan alone ${ }^{4}$.

Once patients are no longer responding to the combined use of a Ts inhibitor and irinotecan or to monotherapy, the options for treatment are limited. Oxaliplatin, a third-generation platinum compound has demonstrated activity in colorectal cancer. Oxaliplatin differs from both cisplatin and carboplatin in its amino acid configuration. Oxaliplatin has an oxalato group that is removed by hydrolysis and replaced with a diaminocyclohexane (DACH) group ${ }^{5}$. The bulky DACH side groups inhibit DNA base excision by mismatching the repair enzymes ${ }^{5}$. Because repair enzymes are particularly active in colorectal cancer, oxaliplatin has the potential to be of great benefit to patients in both first- and second-line treatment. With the availability of randomized trials comparing combination regimens of oxaliplatin and 5-Fu/FA with other combinations, a systematic review of the evidence and clinical practice guideline were warranted.

\section{METHODS}

\subsection{Guideline Development}

This systematic review was developed by the Gastrointestinal Cancer Disease Site Group (GI DSG) of Cancer Care Ontario's Program in Evidence-Based Care (PEBC), using the methods of the practice guidelines development cycle ${ }^{6}$. Evidence was selected and reviewed by two members of the GI DSG and by a methodologist.

The body of evidence in this review is primarily composed of data from mature randomized controlled trials (RCTS). The systematic review and clinical practice guideline are intended to promote evidence-based practice in Ontario, Canada. The PEBC is editorially independent of Cancer Care Ontario and the Ontario Ministry of Health and Long-Term Care.

\subsection{Literature Search Strategy}

A systematic search of the MEDLINE [1966 to June (week 1) 2006], CANCERLIT (1975 to October 2002), EMBASE (week 26, 2003, to week 23, 2006), Guidelines International Network, and Cochrane Library (through Issue 1, 2006) databases was conducted in June 2006. The Medical Subject Heading search terms "colonic 
neoplasms," "rectal neoplasms," and "colorectal neoplasms" were combined with the text words "oxaliplatin", "L-OHP," "LOHP," and "FOLFOX". The results from that search were then combined with the terms "random" and "clinical trial" describing specific study designs. Results were limited to the English language. The conference proceedings of the 1999 to 2006 annual meetings of the American Society of Clinical Oncology, including the 2004 through 2006 gastrointestinal cancer symposia, were also searched for reports of new or ongoing trials. The reference lists from retrieved papers were searched for additional trials.

\subsection{Study Selection Criteria}

Articles were selected for inclusion in this systematic review of the evidence if they were

- $\quad$ phase III RCTS of oxaliplatin (L-OHP) combined with 5-FU/FA as first-line or second-line therapy for advanced colorectal cancer.

- abstract reports of trials.

- English-language published reports.

\subsection{Synthesizing the Evidence}

For the following reasons, the GI DSG decided not to pool the results of the trials found in the literature search:

- Treatments described were too heterogeneous to allow for pooling.

- Evidence from the studies obtained provided a clear indication of benefit or harm.

- Published meta-analyses of individual patient data were available. (The meta-analyses are discussed in the appropriate sections of this report.)

\section{RESULTS}

\subsection{Literature Search Results}

The literature search found thirty-three reports ${ }^{7-39}$, including twenty-seven reports on randomized controlled trials (RCTS) of first-line treatment ${ }^{7-16,18-27}$, 31-37, involving seventeen separate RCTs ${ }^{7-16,31-37}$; two meta-analyses on first-line treatment ${ }^{28,29}$; and four reports on second-line treatment $17,30,38,39$. Ten of these reports were preliminary publications that provided additional information about the included trials ${ }^{18-27}$. Of the thirty-three trial reports obtained, twelve were fully published 7,8,10,11,15,16,28,31,32,34,35,37, and twentyone were available in abstract form only $9,12-14,17-$ $27,29,30,33,36,38,39$. Of the seventeen main reports on first-line treatment, six were available as abstracts only 9,12-14,33,36. All four reports on second-line treatment were available as abstracts only 17,30,38,39.

Sixteen of the included trial reports disclosed funding, either wholly or in part, from pharmaceutical companies $7,8,10,11,15-17,20-22,27,30,31,39$. Seven reported
Debiopharm as the source of funding ${ }^{7,8,10,11,20-22}$; one reported Pharmacia (Pfizer) / Sanofi-Synthelabo ${ }^{15}$; two reported Aventis 16,27; one reported Aventis / Sanofi-Synthelabo ${ }^{31}$; and three reported SanofiSynthelabo ${ }^{17,30,39}$. Five of the reports disclosed a hospital, university, research group, or another non-industry entity as the source of funding ${ }^{32-35,37}$, and twelve trials did not report the source of funding 9,12-14,18,19,23-26,36,38. The reported sources of funding for the two obtained meta-analyses were a research group grant ${ }^{28}$ and partial industry funding ${ }^{29}$.

\subsection{Outcomes}

\subsubsection{Phase III RCTs of Oxaliplatin Combined with 5-FU and FA as First-line Therapy for Advanced Colorectal Cancer}

Twenty-seven reports ${ }^{7-16,18-27,31-37}$ of RCTs on first-line treatment, representing seventeen individual trials ${ }^{7-16}$, 31-37 were obtained (Table I). Six reports of these seventeen trials were available in abstract form only 9,12 , $13,14,33,36$. Results for the outcomes of interest follow.

1-Year Survival: Only seven of the seventeen trials reported 1-year survival data $8,10,11,15,31,32,35$. One of the trials ${ }^{8}$ compared two regimens that both contained 5-FU, FA, and oxaliplatin: one in a standard infusion, and the other in a chronomodulated regimen. Both arms reported similar 1-year survival rates (66\% vs. $63 \%, p>0.05)$. Of the other six trials, only two detected statistically significant 1-year survival differences: one for FOLFOX4 over IFL (71\% vs. 58\%, $p=0.002)^{15}$, and another for OXAFAFU Over IRIFAFU (39\% vs. $23 \%, p=0.032)^{31}$.

Response Rates: Only two of the seventeen trials did not report data on response rates 9,12 . Nine of the 15 trials reported statistically significant differences $(p<0.05)$ in response rates between treatment arms: three for chronomodulated regimens of 5-FU, FA, and oxaliplatin over standard infusion regimens of the same agents $7,8,11$; and the others for LV5FU2 and oxaliplatin over LV5FU2 alone ${ }^{10}$; for FUFOX over FUFA ${ }^{13}$; for FOLFOX 4 over IFL and for IROX Over IFL ${ }^{15}$; for both low- and high-dose OXAFAFU over IRIFAFU ${ }^{31}$; for FOLFOXIRI Over FOLFIRI ${ }^{33}$; and for OXAFAFU over FAFU ${ }^{34}$. One trial that reported on response rates did not report a $p$ value ${ }^{36}$. Three trials reported no significant difference between treatment arms: FOLFOX and FOLFIRI ${ }^{14}$, FOLFOX 4 and IROX ${ }^{15}$, and the crossover trial by Tournigand et al. ${ }^{16}$ that compared the sequences FOLFIRI $\rightarrow$ FOLFOX 6 and FOLFOX $6 \rightarrow$ FOLFIRI.

Quality of Life: Only two of the seventeen RCTs reported data on $\mathrm{QOL}^{10,34}$. Of these latter two trials, neither reported a significant difference in QOL scores between the trial arms: LV5FU2 plus oxaliplatin versus LV5FU $2^{10}$, Or OXAFAFU versus FAFU ${ }^{33}$.

As reported in the RCTs located by the literature search, first-line treatment with oxaliplatin was associ- 
TABLE I Phase III trials of oxaliplatin combined with 5-fluorouracil (5-FU) and folinic acid (FA) as first-line therapy for advanced colorectal cancer

\begin{tabular}{|c|c|c|c|c|c|c|c|c|c|}
\hline Reference & Regimen & $\begin{array}{l}\text { Patients } \\
\text { (n) }\end{array}$ & $\begin{array}{c}\text { ORR } \\
(\% C R+P R)\end{array}$ & $\begin{array}{c}\text { Disease } \\
\text { stabilization } \\
(\%)\end{array}$ & $\begin{array}{c}\text { Median } \\
\text { TTP } \\
\text { (months) }\end{array}$ & $\begin{array}{c}\text { Median } \\
\text { PFS } \\
\text { (months) }\end{array}$ & $\begin{array}{l}\text { Median } \\
\text { survival } \\
\text { (months) }\end{array}$ & $\begin{array}{c}\text { Median } \\
\text { follow-up } \\
\text { time (months) }\end{array}$ & $\begin{array}{l}\text { 1-Year } \\
\text { survival } \\
\quad(\%)\end{array}$ \\
\hline \multicolumn{10}{|l|}{ First-line treatment } \\
\hline \multirow[t]{2}{*}{ Lévi et al., 1994, France ${ }^{7}$} & 5-Fu/FA/oxaliplatin & 47 & $32(2+13)$ & 45 & NR & 8 & 14.9 & 30 & NR \\
\hline & CM 5-FU/FA/oxaliplatin & 45 & $\begin{array}{c}53(3+21) \\
p=0.038\end{array}$ & $\begin{array}{c}33 \\
p=\mathrm{NR}\end{array}$ & $\mathrm{NR}$ & $\begin{array}{c}11 \\
p=\mathrm{NR}\end{array}$ & $\begin{array}{c}19 \\
p=0.03\end{array}$ & & NR \\
\hline \multirow[t]{3}{*}{ Lévi et al., 1997, France ${ }^{8}$} & 5-FU/FA/oxaliplatin & 93 & $29(3+24)$ & $\begin{array}{l}p-\mathrm{NK} \\
\mathrm{NR}\end{array}$ & 4.9 & $\begin{array}{c}p-\mathrm{NK} \\
7.9\end{array}$ & $\begin{array}{c}-0.0 \\
16.9\end{array}$ & 36 & 66 \\
\hline & CM 5-Fu/FA/oxaliplatin & 93 & $51(5+42)$ & $\mathrm{NR}$ & 6.4 & 9.8 & 15.9 & & 63 \\
\hline & & & $p<0.0001$ & & $p=0.006$ & $p=\mathrm{NS}$ & $p=\mathrm{NS}$ & & $p=\mathrm{NS}$ \\
\hline \multirow{5}{*}{$\begin{array}{l}\text { Buechele et al., 2000, } \\
\text { Germany }{ }^{9} \text { (abstract) } \\
\text { de Gramont } \text { et al., 2000, } \\
\text { France }{ }^{10}\end{array}$} & 5-FU/FA/oxaliplatin & NR & NR & NR & NR & NR & NR & NR & NR \\
\hline & 5-FU/FA & NR & $\mathrm{NR}$ & $\mathrm{NR}$ & NR & NR & NR & NR & $\mathrm{NR}$ \\
\hline & LV5Fu2/oxaliplatin & 210 & $50.7(3+102)$ & 31.9 & NR & 9 & 16.2 & 27.7 & 69 \\
\hline & LV5FU2 & 210 & $22.3(1+45)$ & 51.0 & NR & 6.2 & 14.7 & & 61 \\
\hline & & & $p=0.0001$ & $p=\mathrm{NR}$ & & $p=0.0001$ & $p=0.05$ & & $p=\mathrm{NS}$ \\
\hline & CM 5-FU/FA/oxaliplatin & 100 & $53(3+50)$ & 24 & $\mathrm{NR}$ & 8.7 & 19.4 & 47 & $75^{\mathrm{a}}$ \\
\hline \multirow{2}{*}{ France ${ }^{11}$} & $\mathrm{CM} 5$-FU/FA & 100 & $16(0+16)$ & 45 & NR & 6.1 & 19.9 & & $71^{\mathrm{a}}$ \\
\hline & & & $p<0.0001$ & $p=\mathrm{NR}$ & & $p=0.48$ & $p=\mathrm{NS}$ & & $p=\mathrm{NS}$ \\
\hline Giachetti et al., 2002, & CM 5-FU/FA/oxaliplatin & 250 & $\mathrm{NR}$ & $\mathrm{NR}$ & $\mathrm{NR}$ & $\mathrm{NR}$ & $\mathrm{NR}$ & $\mathrm{NR}$ & NR \\
\hline France $^{12}$ (abstract, EORTC trial) & 5-Fu/FA/oxaliplatin & 250 & $\mathrm{NR}$ & $\mathrm{NR}$ & $\mathrm{NR}$ & $\mathrm{NR}$ & $\mathrm{NR}$ & $\mathrm{NR}$ & $\mathrm{NR}$ \\
\hline Grothey et al., $2002^{13}$ & FUFA (Mayo) & 124 & 22.6 & NR & NR & 5.3 & 16.1 & 27.3 & NR \\
\hline \multirow[t]{2}{*}{ (abstract) } & FUFOX & 114 & 48.3 & $\mathrm{NR}$ & $\mathrm{NR}$ & 7.9 & 20.4 & & $\mathrm{NR}$ \\
\hline & & & $p<0.0001$ & & & $p<0.0001$ & $p=\mathrm{NR}$ & & \\
\hline \multirow{3}{*}{$\begin{array}{l}\text { Colucci et al., } 2003^{14} \\
\text { (abstract) }\end{array}$} & FOLFOX & 145 & 36 & 39 & NR & NR & NR & NR & NR \\
\hline & FOLFIRI & 178 & 34 & 44 & NR & NR & NR & NR & NR \\
\hline & & & $p=\mathrm{NS}$ & $p=\mathrm{NR}$ & & & & & \\
\hline \multirow{6}{*}{$\begin{array}{l}\text { Goldberg et al., } 2004^{15} \\
\text { (Intergroup N9741) }\end{array}$} & (A) FOLFOX4 & 267 & 45 & $\mathrm{NR}$ & 8.7 & NR & 19.5 & NR & $71^{\mathrm{a}}$ \\
\hline & (B) IFL & 264 & 31 & NR & 6.9 & NR & 15.0 & $\mathrm{NR}$ & $58^{\text {a }}$ \\
\hline & (C) IROX & 264 & 35 & NR & 6.5 & NR & 17.4 & NR & $65^{\mathrm{a}}$ \\
\hline & & & A vs. B: $p<0.05$ & & A vs. B: $p<0.05$ & & A vs. B: $p<0.05$ & & A vs. B: $p=0.002$ \\
\hline & & & B vs. C: $p<0.05$ & & B vs. C: $p<0.05$ & & B vs. C: $p<0.05$ & & B vs. C: $p=\mathrm{NS}$ \\
\hline & & & A vs. C: $p=\mathrm{NS}$ & & A vs. $C: p=\mathrm{NS}$ & & A vs. C: $p=\mathrm{NS}$ & & A vs. C: $p=\mathrm{NS}$ \\
\hline \multirow[t]{3}{*}{$\begin{array}{l}\text { Tournigand et al., } 2004^{16} \\
\text { (GERCOR) }\end{array}$} & FOLFIRI $\rightarrow$ FOLFOX 6 & 109 & $\begin{array}{l}56(3+58) 1 \text { st line } \\
15(0+12) 2 \text { nd line }\end{array}$ & $\begin{array}{l}23 \text { 1st line } \\
48 \text { 2nd line }\end{array}$ & NR & $\begin{array}{l}8.51 \text { st line } \\
4.2 \text { 2nd line }\end{array}$ & 21.5 & 43.9 & NR \\
\hline & FOLFOX $6 \rightarrow$ FOLFIRI & 111 & $\begin{array}{l}54(5+54) 1 \text { st line } \\
4(0+3) 2 \text { nd line }\end{array}$ & $\begin{array}{l}27 \text { 1st line } \\
30 \text { 2nd line }\end{array}$ & NR & $\begin{array}{l}8.0 \text { 1st line } \\
2.5 \text { 2nd line }\end{array}$ & 20.6 & & $\mathrm{NR}$ \\
\hline & & & $p=\mathrm{NS}$ & $p=\mathrm{NR}$ & & & $p=\mathrm{NS}$ & & \\
\hline \multirow{3}{*}{$\begin{array}{l}\text { Comella et al., } 2005^{31} \\
\text { (sICOG) }\end{array}$} & IRIFAFU & 135 & $31(16+26)$ & 27 & 7.9 & 5.8 & 15.6 & 24 & 23 \\
\hline & OXAFAFU high-dose & 71 & $41(7+22)$ & 21 & 10.5 & & 17.6 & & \\
\hline & OXAFAFU low-dose & 68 & $\begin{array}{c}47(13+19) \\
p=0.029\end{array}$ & 22 & 7.9 & 7.0 & $23+$ & & $\begin{aligned} & 39 \\
p= & 0.032\end{aligned}$ \\
\hline \multirow{2}{*}{$\begin{array}{l}\text { Colucci et al., } 2005^{32} \\
\text { (GOIM) }\end{array}$} & FOLFIRI & 178 & $34(8+48)$ & 42 & 7 & NR & 14 & 31 & 55 \\
\hline & FOLFOX4 & 182 & $\begin{array}{c}36(9+53) \\
p=0.60\end{array}$ & 38 & 7 & NR & 15 & & $\begin{array}{c}62 \\
p>0.05\end{array}$ \\
\hline
\end{tabular}


TABLE I (continued)

\begin{tabular}{|c|c|c|c|c|c|c|c|c|c|}
\hline Reference & Regimen & $\begin{array}{l}\text { Patients } \\
\text { (n) }\end{array}$ & $\begin{array}{c}O R R \\
(\% C R+P R)\end{array}$ & $\begin{array}{c}\text { Disease } \\
\text { stabilization } \\
(\%)\end{array}$ & $\begin{array}{c}\text { Median } \\
\text { TTP } \\
\text { (months) }\end{array}$ & $\begin{array}{c}\text { Median } \\
\text { PFS } \\
\text { (months) }\end{array}$ & $\begin{array}{l}\text { Median } \\
\text { survival } \\
\text { (months) }\end{array}$ & $\begin{array}{c}\text { Median } \\
\text { follow-up } \\
\text { time (months) }\end{array}$ & $\begin{array}{l}\text { 1-Year } \\
\text { survival } \\
\quad(\%)\end{array}$ \\
\hline \multirow{2}{*}{$\begin{array}{l}\text { Falcone } \text { et al., } 2006^{33} \\
\text { (GONO, abstract) }\end{array}$} & FOLFOXIRI & 122 & 66 & NR & NR & 9.8 & 22.6 & 15.2 & NR \\
\hline & FOLFIRI & 122 & $\begin{array}{c}41 \\
p=0.0002\end{array}$ & NR & NR & $\begin{array}{c}6.9 \\
p=0.0006\end{array}$ & $\begin{array}{c}16.7 \\
p=0.032\end{array}$ & & NR \\
\hline \multirow[t]{2}{*}{ Hospers et al., $2006^{34}$} & OXAFAFU & 151 & 33.8 & 43 & NR & 6.7 & 13.8 & 31.8 & NR \\
\hline & FAFU & 151 & $\begin{array}{c}18.5 \\
p=0.004\end{array}$ & 50.3 & NR & 5.6 & 13.3 & & NR \\
\hline \multirow{2}{*}{$\begin{array}{l}\text { Souglakos et al., } 2006^{35} \\
\text { (HORG) }\end{array}$} & FOLFOXIRI & 137 & $43(9+50)$ & NR & 8.4 & NR & 21.5 & 26 & 67 \\
\hline & FOLFIRI & 146 & $\begin{array}{c}33.6(5+44) \\
p=\mathrm{NS}\end{array}$ & NR & $\begin{array}{c}6.9 \\
p=\mathrm{NS}\end{array}$ & NR & $\begin{array}{c}19.5 \\
p=\mathrm{NS}\end{array}$ & & $\begin{array}{c}64 \\
p=\mathrm{NS}\end{array}$ \\
\hline \multirow{3}{*}{$\begin{array}{l}\text { Stanculeanu et al., } 2006^{36} \\
\text { (abstract) }\end{array}$} & FOLFOX4 & 22 & $64(2+12)$ & 27.3 & $\mathrm{NR}$ & NR & $\mathrm{NR}$ & NR & $\mathrm{NR}$ \\
\hline & FOLFIRI & 18 & $44(1+7)$ & 44.4 & NR & NR & NR & NR & NR \\
\hline & IROX & 17 & $\begin{array}{c}53(2+7) \\
p=\mathrm{NR}\end{array}$ & 35.3 & NR & NR & NR & NR & NR \\
\hline \multirow{2}{*}{$\begin{array}{l}\text { Tournigand et al., } 2006^{37} \\
\text { (GERCOR) }\end{array}$} & FOLFOX4 & 311 & 58.5 & NR & NR & 9 & 19.3 & 31 & NR \\
\hline & FOLFOX7 & 309 & $\begin{array}{l}59.2 \\
p=\mathrm{NS}\end{array}$ & NR & NR & 8.7 & 21.2 & & NR \\
\hline \multirow{4}{*}{$\begin{array}{l}\text { Second-line treatment } \\
\text { Rothenberg } \text { et al., } 2003^{30} \\
\text { (abstract, EFC4584) }\end{array}$} & & & & & & & & & \\
\hline & LV5FU2 & 256 & 0 & NR & 2.7 & NR & NR & NR & NR \\
\hline & Oxaliplatin & 266 & NR & NR & NR & NR & NR & NR & NR \\
\hline & FOLFOX4 & 267 & $\begin{array}{c}9.9 \\
p<0.0001\end{array}$ & NR & $\begin{array}{c}4.6 \\
p<0.0001\end{array}$ & NR & NR & NR & NR \\
\hline \multirow{2}{*}{$\begin{array}{l}\text { Garay et al., } 2003^{17} \\
\text { (abstract) }\end{array}$} & FOLFOX4 & 105 & 11.1 & NR & 4.9 & NR & NR & NR & NR \\
\hline & LV5Fu2 & 101 & $\begin{array}{c}1.9 \\
p<0.05\end{array}$ & NR & $\begin{array}{c}2.6 \\
p<0.05\end{array}$ & NR & NR & NR & NR \\
\hline \multirow{3}{*}{$\begin{array}{l}\text { Giantonio et al., } 2005^{38} \\
\text { (abstract, ECOG) }\end{array}$} & (A) FOLFOX4+bevacizumab & 290 & NR & NR & $\mathrm{NR}$ & 7.4 & 12.5 & NR & NR \\
\hline & (B) FOLFOX4 & 289 & NR & NR & NR & 5.5 & 10.7 & NR & NR \\
\hline & (C) Bevacizumab & 243 & NR & NR & NR & $\begin{array}{c}3.5 \\
\text { A vs. B: } \\
p=0.0003\end{array}$ & $\begin{array}{c}10.2 \\
\text { A vs. B: } \\
p=0.0024\end{array}$ & NR & NR \\
\hline \multirow{2}{*}{$\begin{array}{l}\text { Pitot et al., } 2005^{39} \\
\text { (abstract, N9841) }\end{array}$} & CPT $-11 \rightarrow$ FOLFOX 4 & 245 & 15 & NR & 4.0 & $\mathrm{NR}$ & 14.7 & NR & NR \\
\hline & FOLFOX $4 \rightarrow$ CPT- 11 & 246 & $\begin{array}{c}27 \\
\mathrm{p}<0.01\end{array}$ & NR & 5.2 & NR & 13.5 & NR & NR \\
\hline
\end{tabular}

a Estimated from survival curve.

$\mathrm{ORR}=$ overall response rate; $\mathrm{CR}=$ complete response; $\mathrm{PR}=$ partial response; $\mathrm{TTP}=$ time to progression; $\mathrm{PFS}=$ progression-free survival; $\mathrm{NR}=$ not reported; $\mathrm{CM}=$ chronomodulated delivery rate; $\mathrm{NS}=$ nonsignificant; LV5FU2 $=$ leucovorin calcium $(\mathrm{FA}), 5-\mathrm{FU} ;$ EORTC $=$ European Organization for Research and Treatment of Cancer; FUFA $=5$-FU, FA; FUFOX $=5$-FU, FA, oxaliplatin; FOLFOX (appended digit indicates regimen variation) = FA, 5-FU, oxaliplatin; FOLFIRI = FA, 5-FU, irinotecan; IFL = irinotecan, 5-FU, leucovorin calcium $(\mathrm{FA})$; IROX $=$ irinotecan, oxaliplatin; GERCOR = Groupe Coopérateur Multidisciplinaire en Oncologie; sICOG = Southern Italy Cooperative Oncology Group; IRIFAFU = irinotecan, FA, 5-FU; OXAFAFU = oxaliplatin, FA, 5-FU; GOIM = Gruppo Oncologico Italia Meridionale; FOLFOXIRI = FA, 5-FU, oxaliplatin, irinotecan; GONO = Gruppo Oncologico Nord Ovest; OXAFAFU = oxaliplatin, FA, 5-FU; FAFU = $\mathrm{FA}, 5-\mathrm{FU} ; \mathrm{ECOG}=$ Eastern Cooperative Oncology Group; $\mathrm{CPT}-11=$ irinotecan. 
ated with significantly more peripheral and sensory neuropathy and neutropenia beyond the adverse effects expected with the other drugs given in the regimen.

\subsubsection{Meta-analyses of First-line Trials}

The meta-analysis reported by Grothey et al. ${ }^{28}$ included the fully published or publicly presented results from seven RCTS involving 3186 patients. It detected a significant 3.5-month increase in median survival ( $p=0.0083$ ) in patients who received a firstline combination therapy (either oxaliplatin/5-Fu/FA or irinotecan/5-FU/FA) as compared with patients who received monotherapy. The results of the meta-analysis indicated that, for maximum overall survival benefit, patients on a first-line combination therapy containing oxaliplatin should be offered combination therapy with irinotecan as second-line treatment, and vice versa. It appears that second-line treatment may compensate for a less active first-line treatment, as evidenced by the fact that patients who had access to all three active drugs (oxaliplatin, irinotecan, and $5-\mathrm{Fu}$ ) showed the longest overall survival. However, this conclusion is confounded by the fact that patients who lived longer were more likely to have been treated with all three drugs. In addition, patients with lower performance status may have been excluded from second-line treatments using oxaliplatin and irinotecan. Additionally, oxaliplatin was not available to all patients, especially in older trials. The metaanalysis detected longer median survival times in more recent trials-trials more likely to use oxaliplatin in first- and second-line treatment.

An abstract report by Lévi et al. ${ }^{29}$ pooled the 7-year results of two previously discussed, but individually underpowered, trials ${ }^{7,8}$. Both trials compared chronomodulated (CM) infusion to flat infusion in the first-line treatment of MCC. Significant benefits were detected in overall response rate (ORR\%: $51 \%$ vs. $30 \%$; $p<0.001)$, complete surgical resection $(23.3 \%$ vs. $12.8 \%, p<0.001$ ), and median progression-free survival (PFS: 10.3 months vs. 7.5 months; $p=0.039$ ) favouring CM therapy; however, no difference was detected in median survival (18.6 months vs. 16.5 months, $p=0.22$ ). Pooling the data from the two trials did not detect any difference in survival at either 5 or 7 years (5-year survival: $12.6 \%$ vs. $15.2 \%$; 7 -year survival: $6.6 \%$ vs. $7.1 \%$ ). The results may have been confounded by an imbalance between the studies with regard to recurrent metastatic disease following surgery for liver metastases $(10 \%$ of patients receiving flat infusion vs. $22 \%$ of patients receiving $\mathrm{CM}$ infusion, $p<0.001$ ), and in addition, by significant treatment crossover from the flat infusion to the СM infusion arm (26\% of patients), which affected median survival (14.7 months non-crossover vs. 18.5 months crossover; $p=0.043$ ). The pooled results from those two trials confirmed that, as compared with flat infusion, CM infusion significantly improved the ORR \% and PFS.

\subsubsection{Phase III RCTs of Oxaliplatin Combined with 5-FU and FA as Second-line Therapy for Advanced Colorectal Cancer}

Four reports ${ }^{17,30,38,39}$ describing four RCTs of secondline treatment were obtained (Table I). All of these trial reports were available in abstract form only.

1-Year Survival: None of the second-line treatment reports obtained provided data on 1-year survival.

Response Rates: Three of the four reports ${ }^{17,30,39}$ provided data on response rates. All three trials reported statistically significant differences between the trial arms, two for FOLFOX 4 over LV5FU $2{ }^{17,30}(9.9 \%$ vs. $0 \%$, $p<0.0001^{30} ; 11.1 \%$ vs. $1.9 \%, p<0.05^{17}$ ), and the third for the sequence FOLFOX $4 \rightarrow$ CPT- 11 over CPT- $11 \rightarrow$ FOLFOX4 $(27 \% \text { vs. } 15 \%, p<0.0142)^{39}$.

Quality of Life: None of these abstract reports provided data on QOL.

As indicated under the heading "Quality of Life" in subsection 4.2.1, treatment with oxaliplatin was associated with significantly more peripheral and sensory neuropathy and neutropenia beyond the adverse effects expected from other drugs given in the regimen.

\section{INTERPRETIVE SUMMARY}

The combination regimens using infusional 5-FU (FOLFOX or FOLFIRI) both represent acceptable treatment alternatives for first-line therapy in fit patients.

Oxaliplatin is active in colorectal cancer, and the evidence supports its use in combination with infusional 5-FU/FA (FOLFOX). Oxaliplatin without 5-FU/FA does not appear to have meaningful activity. The FOLFOX regimen has definite advantages over bolus IFL in terms of toxicity, objective response rate ( $45 \%$ vs. $31 \%)$, median TTP (8.7 months vs. 6.9 months), median survival (19.5 months vs. 15.0 months), and 1-year survival (71\% vs. $58 \%$ ) as demonstrated in the N9741 study ${ }^{15}$.

The superior 1-year survival seen in the N9741 study may have two possible explanations:

- The 5-Fu was given as an infusion in the FOLFOX arm, but as a bolus in the IFL arm, and infusional 5-Fu has demonstrated superiority over bolus 5-FU in terms of toxicity and tumour response rate. This fact alone may therefore account for the differences seen in the two regimens. It may also account for the lack of difference seen between FOLFOX and FOLFIRI in the GERCOR study, because both regimens used infusional 5-Fu ${ }^{16}$.

- Superior survival in the FOLFOX arm may relate to the high rate of second-line irinotecan use. In the FOLFOX arm, 53\% of the patients received secondline irinotecan, but only $17 \%$ of patients on the IFL arm received second-line oxaliplatin. It is becoming increasingly clear that subsequent therapy can have a substantial effect on survival. From 
the evidence reviewed, it appears that the number of active drugs available to a study arm may positively affect survival, because when more drugs are made available to patients, median survival is increased. This finding does not rule out other factors, such as variations in study population and other variations in treatment over time, but it is highly supportive of the conclusion that access to all three active drugs (5-FU/FA, oxaliplatin, irinotecan) is important to optimize patient outcomes $^{27}$. It is also evident that when combination therapy is to be used, infusional rather than bolus 5-Fu should be used. This recommendation to use 5-Fu in an infusional schedule is now abundantly clear from single-agent studies, from combination studies in advanced disease, and from the adjuvant setting in early colorectal cancer. The role of bolus 5-Fu in the management of colorectal cancer is becoming increasingly limited.

The combination of oxaliplatin and irinotecan is also active, but it has lower tumour response rates and 1-year survival rates than FOLFOX does, and therefore no advantages ${ }^{15}$.

The inconvenience of infusional 5-Fu pump programs, in combination with the drug's unavailability in certain regions, has led to interest in oral capecitabine as a possible replacement for infusional 5-FU in oxaliplatin and irinotecan combinations. The few phase II trials reported thus far have demonstrated response rates and toxicity that appear comparable to those seen with infusional 5-Fu combinations. In the future, capecitabine may supersede the 5-Fu pump and the need for central venous access devices; however, this development will depend on the results of ongoing phase III trials. Until the results of those trials are available, infusional 5-Fu regimens-either alone or in combination-are standard therapy.

The question of whether to use a CM regimen of infusional 5-Fu is a compelling area of study, but no such regimen has been widely evaluated outside of a few specialized centres. This question extends beyond a simple review of 5-Fu/oxaliplatin combinations. The pooled analysis of the two underpowered studies by Lévi et al. ${ }^{7,8}$ suggests that CM could both reduce toxicity and positively affect endpoints such as ORR\% and TTP. The intervention is worthy of further study, although the complexity of the therapy may put it beyond feasibility in many locales.

The ECF4584 trial $^{30}$ demonstrated improvements in response rate, ТTP (median: 4.6 months vs. 1.6 months, $p<0.0001)$, and symptom control with second-line FOLFOX as compared with oxaliplatin alone or infusional 5-FU/FA alone in patients who progressed on the ILF regimen. No overall survival analysis was performed. For patients who have progressed on both an anti-Ts agent and irinotecan, FOLFOX is the preferred therapy.

In patients with tumour progression on first-line 5-FU/FA, FOLFOX is active, with an ORR \% that appears to compare favourably with that of FOLFIRI, the standard regimen. Currently, more evidence supports second-line irinotecan than supports FOLFOX or oxaliplatin alone, but for patients considered poor candidates for second-line irinotecan, FOLFOX is a reasonable alternative. Further clarification of the role of oxaliplatin after progression on first-line 5-Fu awaits more-mature data from the Sanofi-sponsored ECF4585 trial.

As treatment regimens for advanced colorectal cancer continue to evolve, recent trials ${ }^{38,40}$ have investigated the addition of bevacizumab to the FOLFOX regimen. An abstract report by Hochster et al. ${ }^{40}$ of the TREE-2 study - a first-line cohort study comparing FOLFOX plus bevacizumab, OXAFAFU plus bevacizumab, and capecitabine and oxaliplatin (CAPOx) plus bevacizumab-found that FOLFOX plus bevacizumab resulted in the longest median survival with acceptable adverse events. In the TREE- 2 study, the median survivals for the treatment arms without bevacizumab were 19.2 months (FOLFOX), 17.9 months (OXAFAFU), and 17.3 months (CAPOX) as compared with 26 months (FOLFOX + bevacizumab), 20.7 months (OXAFAFU + bevacizumab), and 27.0 months (CAPOX + bevacizumab) ${ }^{41}$. The overall median survival was 18.2 months (no bevacizumab) as compared with 24.4 months (bevacizumab added) ${ }^{41}$. When the overall survival data from the TREE-1 trial (no bevacizumab) were compared with the TREE- 2 trial data (bevacizumab added), the results were 12 months, $67.5 \%$ versus $79.1 \%$; 18 months, $50.1 \%$ versus $64.7 \%$; 24 months, $35.8 \%$ versus $50.7 \%$ all in favour of the treatments including bevacizumab ${ }^{41}$.

The second-line $\mathrm{RCT}$ reported by Giantonio et al. ${ }^{38}$, which compared FOLFOX 4 with and without bevacizumab, found that the addition of bevacizumab to the FOLFOX regimen resulted in significant gains in both median survival (10.7 months vs. 10.2 months, $p=0.0024)$ and PFs (7.4 months vs. 5.5 months, $p=0.0003)$. Based on these two trials, we conclude that the addition of bevacizumab to an infusional 5-Fu, FA, and oxaliplatin regimen may provide benefits beyond those that would be possible with infusional 5-FU, FA, and oxaliplatin without bevacizumab.

\section{GASTROINTESTINAL CANCER DSG CONSENSUS PROCESS}

Note: The GI DSG consensus process was based on an earlier draft of the present document. That draft did not contain any of the evidence regarding the addition of bevacizumab to regimens of infusional 5-FU/FA plus oxaliplatin. References 15 and 31-41 were added to the document after the consensus process took place.

The systematic review found one first-line therapy trial ${ }^{15}$ that demonstrated infusional 5-Fu/FA/ oxaliplatin (FOLFOX) to be superior to bolus 5-Fu/FA/ irinotecan (IFL), with more favourable rates of median survival and tumour response. Compared with IFL, FOLFOX has lower incidences of severe nausea, vomiting, diarrhea, and febrile neutropenia, but a 
higher incidence of peripheral neuropathy. Therefore, for first-line treatment, short-term infusional 5-FU/FA in combination with either oxaliplatin (FOLFOX) or irinotecan (FOLFIRI) is acceptable for fit patients when combination therapy is the preferred treatment. Choice of first-line therapy may rely on patient factors and preferences-for example, less neuropathy with irinotecan versus less alopecia with oxaliplatin.

For second-line treatment after progression on first-line anti-Ts monotherapy (for example, 5-FU/FA, capecitabine), irinotecan is standard therapy. For patients with contraindications to the use of secondline irinotecan, FOLFOX is a reasonable alternative. After progression on both irinotecan and an anti-TS agent, FOLFOX is the preferred therapy.

The role of radiation therapy, either alone or in combination with chemotherapy, for locally advanced unresectable colorectal cancer was not addressed in this guideline. In addition, the use of $\mathrm{CM}$ regimens is a topic that intersects with the use of oxaliplatin/5-Fu combinations, particularly $\mathrm{CM} 5-\mathrm{FU}$ in those combinations. Chronomodulation of oxaliplatin has not been extensively studied and was not addressed, because the topic is beyond the scope of this guideline.

In conclusion, the GI DSG acknowledges that the combination of oxaliplatin with short-term infusional 5-FU and FA (FOLFOX) is an important component of first- and second-line treatment of advanced colon cancer, and the DSG recommends that oxaliplatin be made available for the treatment of advanced colorectal cancer.

\section{EXTERNAL REVIEW OF THE PRACTICE GUIDELINE REPORT}

Note: The practitioner feedback survey was based on an earlier draft of the present document. That draft did not contain any of the evidence regarding the addition of bevacizumab to infusional regimens of 5-FU/FA plus oxaliplatin. References 15 and 31-41 were added to the document after the practitioner feedback survey was complete.

Based on the evidence and the draft recommendations presented at the time of GI DSG consensus, feedback was sought from Ontario clinicians.

\subsection{Methods}

Practitioner feedback was obtained through a mailed survey of 63 practitioners in Ontario (11 medical oncologists, 9 radiation oncologists, 42 surgeons, and one other practitioner). The survey consisted of items evaluating the methods, results, and interpretive summary used to inform the draft recommendations and asking whether the draft recommendations should be approved as a practice guideline. Written comments were invited. The practitioner feedback survey was mailed September 15, 2004. Follow-up reminders were sent at 2 weeks (post card) and 4 weeks (com- plete package mailed again). The GI DSG reviewed the results of the survey.

\subsection{Results}

From among the 63 surveys distributed, 29 responses were received (46\% response rate). "Responses" include returned completed surveys and telephone, fax, and e-mail responses. Of the practitioners who responded, 18 indicated that the report was relevant to their clinical practice, and they completed the survey. Table II summarizes key results of the practitioner feedback survey.

\subsection{Summary of Written Comments}

Four respondents $(22 \%)$ provided written comments. The main points were these:

- Access issues with oxaliplatin are ongoing.

- The guidelines seem to be directed to the medical oncologists who provide the treatments. For other caregivers in the cancer system, this key message needs to be delivered: Cancer treatment is in a state of continuous development with increasing efficacy, therefore assessment by a medical oncologist is important for all patients.

- Some of the stated recommendations are currently in use and are being accepted with enthusiasm by both clinicians and patients.

- This guideline has not included any information regarding the role of radiation in the local management of rectal tumours. However, the guideline makes good sense with respect to the recommended chemotherapy regimens. Could a recommendation, or at least a comment, be added somewhere in the document regarding radiation timing, and radiation in combination with the recommended chemotherapy regimens?

\subsection{Modifications/Actions}

The GI DSG made the following modifications to the clinical practice guideline in response to the comments obtained during practitioner feedback:

- With respect to the ongoing access issues with oxaliplatin, the GI DSG acknowledges the major barrier that access represents to putting its recommendations into practice. The GI DSG hopes that their recommendation of oxaliplatin will raise awareness of the issue and facilitate the process of making this drug available to patients.

- With respect to the issue of radiation therapy, the GI DSG added a qualifying statement to both the abstract and the main document: "The role of radiation therapy, either alone or in combination with chemotherapy, for locally advanced unresectable colorectal cancer is not addressed in this guideline." 
TABLE II Practitioner responses to eight items on the practitioner feedback survey

Item

Percentage who

Strongly agree or agree Neither agree nor disagree Strongly disagree or disagree

The rationale for developing a clinical practice guideline, as stated in the "Choice of Topic" section of the report, is clear.

There is a need for a clinical practice guideline on this topic.

The literature search is relevant and complete.

The results of the trials described in the report are interpreted according to my understanding of the data.

The draft recommendations in this report are clear.

I agree with the draft recommendations as stated.

This report should be approved as a practice guideline.

100
89
78
89
78
83
89

\begin{tabular}{lccc}
\hline & Very likely or likely & Unsure & Not at all likely or unlikely \\
\hline $\begin{array}{l}\text { If this report were to become a practice guideline, } \\
\text { how likely would you be to make use of it in your } \\
\text { own practice? }\end{array}$ & 67 & 11 & 11 \\
\hline
\end{tabular}

\section{REFERENCES}

1. Holowaty EJ, Marret LD, Parkes R, Fehringer G. Colorectal Cancer in Ontario 1971-1996: Incidence and Mortality in Ontario. Toronto: Division of Preventative Oncology, Cancer Care Ontario. 1998: 1.

2. Jonker D, Earle C, Kocha W, Moore M, Maroun J, Zuraw L, for the Gastrointestinal Cancer Disease Site Group. Use of irinotecan combined with 5-fluorouracil and leucovorin as firstline therapy for metastatic colorectal cancer. Curr Oncol 2001; 8:60-8.

3. Germond C, Maroun J, Zwaal C, Wong S, for the Gastrointestinal Cancer Disease Site Group. Use of raltitrexed in the management of metastatic colorectal cancer. Curr Oncol 1999; $6: 217-23$.

4. Figueredo A, Moore M, Germond C, Kocha W, Maroun J, Zwaal C, for the Gastrointestinal Cancer Disease Site Group. Use of irinotecan in second-line treatment of metastatic colorectal carcinoma. Curr Oncol 2000;7:29-36.

5. Hochster H, Chachoua A, Speyer J, Escalon J, ZeleniuchJacquotte A, Muggia F. Oxaliplatin with weekly bolus fluorouracil and low-dose leucovorin as first-line therapy for patients with colorectal cancer. J Clin Oncol 2003;21:2703-7.

6. Browman GP, Levine MN, Mohide EA, et al. The practice guidelines development cycle: a conceptual tool for practice guidelines development and implementation. J Clin Oncol 1995;13:502-12.

7. Lévi FA, Zidani R, Vannetzel JM, et al. Chronomodulated versus fixed-infusion-rate delivery of ambulatory chemotherapy with oxaliplatin, fluorouracil, and folinic acid (leucovorin) in patients with colorectal cancer metastases: a randomized multi-institutional trial. J Natl Cancer Inst 1994;86: 1608-17.

8. Lévi F, Zidani R, Misset J. Randomised multicentre trial of chronotherapy with oxaliplatin, fluorouracil, and folinic acid in metastatic colorectal cancer. Lancet 1997;350:681-6.
9. Buechele T, Kroening H, Reichardt $\mathrm{P}$, et al. Bolus 5-fluorouracil (5-FU)/folinic acid (FA) (Mayo Clinic) versus weekly, highdose 24h 5-Fu infusion + FA plus oxaliplatin (LOHP) in advanced colorectal cancer (CRC). A randomized phase III trial (abstract 984). Proc Am Soc Clin Oncol 2000;19:253a.

10. de Gramont A, Figer A, Seymour M, et al. Leucovorin and fluorouracil with or without oxaliplatin as first-line treatment in advanced colorectal cancer. J Clin Oncol 2000;18:2938-47.

11. Giacchetti S, Perpoint B, Zidani R, et al. Phase III multicenter randomized trial of oxaliplatin added to chronomodulated fluorouracil-leucovorin as first-line treatment of metastatic colorectal cancer. J Clin Oncol 2000;18:136-47.

12. Giacchetti S, Bjarnason G, Garufi C, et al. First line infusion of 5-fluorouracil, leucovorin, oxaliplatin for metastatic colorectal cancer chronomodulated versus conventional delivery. A multicenter randomized trial of the EORTC chronotherapy group (abstract 2231). Proc Am Soc Clin Oncol 2002; 21:104b.

13. Grothey A, Deschler B, Kroening H, et al. Phase III study of bolus 5-fluorouracil (5-Fu)/folinic acid (FA) (Mayo) vs. weekly high-dose $24 \mathrm{hr}$ 5-Fu infusion/FA + oxaliplatin (OXA) (FUFOX) in advanced colorectal cancer (ACRC) (abstract 512). Proc Am Soc Clin Oncol 2002;21:129a.

14. Colucci G, Maiello E, Gebbia V, et al. Preliminary results of a randomized multicenter trial of the Gruppo Oncologico Italia Meridionale (GOIM) comparing FOLFIRI vs. FOLFOX in advanced colorectal cancer (ACC) patients (abstract 1021). Proc Am Soc Clin Oncol 2003;22:255.

15. Goldberg RM, Sargent DJ, Morton RF, et al. A randomized controlled trial of fluorouracil plus leucovorin, irinotecan, and oxaliplatin combinations in patients with previously untreated metastatic colorectal cancer. J Clin Oncol 2004;22:23-30.

16. Tournigand $\mathrm{C}$, André $\mathrm{T}$, Achille E, et al. FOLFIRI followed by FOLFOX6 or the reverse sequence in advanced colorectal cancer: a randomized GERCOR study. J Clin Oncol 2004;22:229-37.

17. Garay CA, Kemeny N, Gurtler J, et al. Randomized trial of 
bolus plus infusional 5-Fu/leucovorin (LV5FU2) with/without oxaliplatin (FOLFOX4) after sequential fluoropyrimidine and CPT-11 in the treatment of advanced colorectal cancer (ACRC) (abstract 1019). Proc Am Soc Clin Oncol 2003;22:254.

18. Figer A, Louvet $\mathrm{C}$, Homerin $\mathrm{M}$, et al. Analysis of prognostic factors of overall survival (os) in the randomized trial of bimonthly leucovorin and 5-fluorouracil regimen (LV5FU2) with or without oxaliplatin (OXA) in advanced colorectal cancer (ACC) (abstract 918). Proc Am Soc Clin Oncol 1999;18:239a.

19. Seymour MT, Tabah-Fisch I, Homerin M. Quality of life (QOL) in advanced colorectal cancer (ACC): a comparison of QOL during bolus plus infusion 5-Fu/leucovorin (Lv5Fu2) with or without oxaliplatin (abstract 901). Proc Am Soc Clin Oncol 1999; 18:234a.

20. de Gramont A, Figer A, Seymour M, et al. A randomized trial of leucovorin (LV) and 5-fluorouracil (5-FU) with or without oxaliplatin in advanced colorectal cancer (CRC) (abstract 985). Proc Am Soc Clin Oncol 1998; 17:257a.

21. Giacchetti S, Brienza S, Focan C, et al. Contribution of second-line oxaliplatin (OXA)-chronomodulated 5-fluorouracilfolinic acid (CM-5-FU-FA) and surgery to survival in metastatic colorectal cancer patients (MCC pts) (abstract 1050). Proc Am Soc Clin Oncol 1998; 17:273a.

22. Giacchetti S, Zidani R, Perpoint B, et al. Phase III trial of 5-fluorouracil (5-FU), folinic acid (FA), with or without oxaliplatin (OXA) in previously untreated patients (pts) with metastatic colorectal cancer (MCC) (abstract 805). Proc Am Soc Clin Oncol 1997; 16:229a.

23. Grothey A, Deschler B, Kroening H, et al. Bolus 5-fluorouracil (5-Fu)/folinic acid (FA) (Mayo) vs. weekly high-dose $24 \mathrm{~h}$ 5-FU infusion/FA + oxaliplatin (OXA) in advanced colorectal cancer (CRC). Results of a phase III study (abstract 496). Proc Am Soc Clin Oncol 2001;20:125a.

24. Colucci G, Maiello E, Paoletti G, et al. Fluorouracil (FU) plus folinic acid (FA) with irinotecan (CPT-11) or oxaliplatin (OHP) in advanced colorectal cancer (ACC) patients: preliminary safety results of a randomized phase II multicentre trial of the Gruppo Oncologico Italia Meridionale (GOIM) (abstract 652). Proc Am Soc Clin Oncol 2002;21:164a.

25. Goldberg RM, Morton RF, Sargent DJ, et al. N9741: oxaliplatin (OXAL) or CPT-11 + 5-fluorouracil (5-Fu)/leucovorin (LV) or OXAL + CPT-11 in advanced colorectal cancer (CRC). Updated efficacy and quality of life (QOL) data from an Intergroup study (abstract 1009). Proc Am Soc Clin Oncol 2003;22:252.

26. Goldberg RM, Morton RF, Sargent DJ, et al. N9741: oxaliplatin (OXAL) or CPT-11 + 5-fluorouracil (5-FU)/leucovorin (LV) or OXAL + CPT-11 in advanced colorectal cancer (CRC). Initial toxicity and response data from a GI Intergroup study (abstract 511). Proc Am Soc Clin Oncol 2002;21:128a.

27. Tournigand C, Louvet C, Quinaux E, et al. FOLFIRI followed by FOLFOX versus FOLFOX followed by FOLFIRI in metastatic colorectal cancer (MCRC): final results of a phase III study (abstract 494). Proc Am Soc Clin Oncol 2001;20:124a.

28. Grothey A, Sargent D, Goldberg RM, Schmoll HJ. Survival of patients with advanced colorectal cancer improves with the availability of fluorouracil-leucovorin, irinotecan, and oxaliplatin in the course of treatment. J Clin Oncol 2004;22: 1209-14.

29. Lévi FA, Zidani R, Llory J, et al. Final efficacy update at 7 years of flat vs. chronomodulated infusion (chrono) of oxaliplatin, 5-fluorouracil and leucovorin as first-line treatment of metastatic colorectal cancer (abstract 936). Proc Am Soc Clin Oncol 2000;19:242a.

30. Rothenberg ML, Oza AM, Burger B, et al. Superiority of oxaliplatin and fluorouracil-leucovorin compared with either therapy alone in patients with progressive colorectal cancer after irinotecan and fluorouracil-leucovorin: interim results of a phase III trial. J Clin Oncol 2003;21:2059-69.

31. Comella P, Massidda B, Filippelli G, et al. Oxaliplatin plus high-dose folinic acid and 5-fluorouracil i.v. bolus (OXAFAFU) versus irinotecan plus high-dose folinic acid and 5-fluorouracil i.v. bolus (IRIFAFU) in patients with metastatic colorectal carcinoma: a Southern Italy Cooperative Oncology Group phase III trial. Ann Oncol 2005;16:878-86.

32. Colucci G, Gebbia V, Paoletti G, et al. Phase III randomized trial of FOLFIRI versus FOLFOX4 in the treatment of advanced colorectal cancer: a multicentre study of the Gruppo Oncologico Dell'Italia Meridionale. J Clin Oncol 2005;23: 4866-75.

33. Falcone A, Masi G, Brunetti I, et al. The triplet combination of irinotecan, oxaliplatin, and 5FU/LV (FOLFOXIRI) vs the doublet of irinotecan and 5FU/LV (FOLFIRI) as first-line treatment of metastatic colorectal cancer (MCRC): results of a randomized phase III trial by the Gruppo Oncologico Nord Ovest (GONO) (abstract 3513). Proc Am Soc Clin Oncol 2006;24:149a.

34. Hospers GAP, Schaapveld M, Nortier JWR, et al. Randomization of phase III study of biweekly 24-h infusion of highdose 5-Fu with folinic acid and oxaliplatin versus monthly plus 5-Fu/folinic acid in first-line treatment of advanced colorectal cancer. Ann Oncol 2006;17:443-9.

35. Souglakos J, Androulakis N, Syrigos K, et al. FOLFOXIRI (folinic acid, 5-fluorouracil, oxaliplatin and irinotecan) vs FOLFIRI (folinic acid, 5-fluorouracil and irinotecan) as first-line treatment in metastatic colorectal cancer (MCC): a multicentre randomized phase III trial from the Hellenic Oncology Research Group (HORG). Br J Cancer 2006;94:798-805.

36. Stanculeanu DL, Matache R, Minea L, Cringeanu A, Anghel R. FOLFOX-4 vs. FOLFIRI vs. IROX as first line chemotherapy for metastatic colon cancer: efficacy and toxicity (abstract 13541). Proc Am Soc Clin Oncol 2006;24:619s.

37. Tournigand C, Cervantes A, Figer A, et al. optimox1: a randomized study of FOLFOX 4 or FOLFOX7 with oxaliplatin in a stopand-go fashion in advanced colorectal cancer-a GERCOR study. J Clin Oncol 2006;24:394-400.

38. Giantonio BJ, Catalano PJ, Meropol NJ, et al. High-dose bevacizumab improves survival when combined with FOLFOX4 in previously treated advanced colorectal cancer: results from the Eastern Cooperative Oncology Group (ECOG) study E3200 (abstract 2). Proc Am Soc Clin Oncol 2005;23:1s.

39. Pitot HC, Rowland KM, Sargeant DJ, et al. N9841: a randomized phase III equivalence trial of irinotecan (CPT-11) versus oxaliplatin/5-fluorouracil (5FU)/leucovorin (FOLFOX4) in patients (pts) with advanced colorectal cancer (CRC) previously treated with 5Fu (abstract 3506). Proc Am Soc Clin Oncol 2005; 23:247s.

40. Hochster HS, Hart LL, Ramanathan RK, et al. Results of the TREE- 2 cohort: safety, tolerability, and efficacy of bevacizumab added to three oxaliplatin/fluorouracil regimens as first-line 
treatment of metastatic colorectal cancer (abstract 244). Proc Am Soc Clin Oncol (Gastrointest Cancer Symp) 2006.

41. Hochster HS. Safety and efficacy of oxaliplatin/fluoropyrimidine regimens with or without bevacizumab as first-line treatment of metastatic colorectal cancer $(\mathrm{mCRC})$ : final analysis of the TREE-study (abstract 3510). J Clin Oncol 2006;24(June 20 suppl):148s. [Virtual presentation available online at: ww w.asco.org/portal/site/ A S CO/menuitem .34d60f5624ba07fd506fe310ee37a01d/?vgnextoid= 76f8201eb61a7010VgnVCM100000ed730ad1RCRD\&vmview= abst_detail_view\&confID=40\&abstractID=33907; accessed July 5, 2006]
Correspondence to: R. Bryan Rumble, Research Coordinator, Gastrointestinal Cancer Disease Site Group, Cancer Care Ontario's Program in Evidence-Based Care, McMaster University, 50 Main Street East, DTC, 3rd floor, Room 319, Hamilton, Ontario L8N 1 E9.

E-mail: rumbleb@mcmaster.ca

* Please see the Cancer Care Ontario Program in Evidence-Based Care's Web site for a complete list of Gastrointestinal Cancer Disease Site Group members (www.cancercare.on.ca/index AboutthePEBC.htm\#dsg).

APPENDIX A Treatment options (refer to Appendix в for recommended dosages and schedules)

First-line treatment alternatives FOLFIRI (combination 5-FU/FA/irinotecan) FOLFOX (combination 5-FU/FA/oxaliplatin) de Gramont schedule (infusional 5-Fu/FA)

Raltitrexed

Capecitabine
Second-line treatment alternatives

FOLFOX (combination 5-FU/FA/oxaliplatin), after first-line FOLFIRI FOLFIRI (combination 5-FU/FA/irinotecan), after first-line FOLFOX FOLFOX (combination 5-FU/FA/oxaliplatin), plus bevacizumab Irinotecan alone

APPENDIX B Dosing by trial

\begin{tabular}{|c|c|}
\hline Reference & Regimen (mg/m² daily, frequency) \\
\hline \multicolumn{2}{|l|}{ First-line treatment } \\
\hline Lévi et al., $1994^{7}$ & $\begin{array}{l}\text { 5-Fu } 600 \text {, FA } 300 \text {, oxaliplatin } 20 \text {, days } 1-5 \text {, every } 21 \text { days (16-day intermission) via programmable } \\
\text { pump }\end{array}$ \\
\hline \multirow[t]{2}{*}{ (IOCC trial) } & Arm A: flat infusion \\
\hline & Arm B: CM infusion (5-Fu/FA peak at 04:00 hours; oxaliplatin peak at 16:00 hours) \\
\hline \multirow{3}{*}{$\begin{array}{l}\text { Lévi et al., } 1997^{8} \\
\text { (IOCC trial) }\end{array}$} & 5 -Fu 600 , FA 300 , oxaliplatin 20 , days $1-5$, every 21 days (16-day intermission) \\
\hline & Arm A: flat infusion \\
\hline & Arm B: $\mathrm{CM}$ infusion \\
\hline \multirow[t]{2}{*}{ Buechele et al., 2000, Germany ${ }^{9}$} & $\begin{array}{l}\text { Oxaliplatin } 50,2 \text {-hour infusion + FA } 500,2 \text {-hour infusion }+5 \text {-Fu } 2000,24 \text {-hour infusion; days } 1,8 \text {, } \\
15 \text {, and } 22 \text {; every } 36 \text { days versus }\end{array}$ \\
\hline & Bolus 5-Fu/FA (Mayo Clinic regimen) \\
\hline \multirow[t]{2}{*}{ de Gramont et al., $2000^{10}$} & $\begin{array}{l}\text { Oxaliplatin } 85,2 \text {-hour infusion, day } 1+5 \text {-Fu } 400 \text { bolus, then } 600 \text { continuous infusion, days } 1 \text { and } \\
2+\text { FA } 200 \text { continuous infusion, days } 1 \text { and } 2 \text { every } 2 \text { weeks versus }\end{array}$ \\
\hline & $\begin{array}{l}5 \text {-Fu } 400 \text { bolus, then } 600 \text { continuous infusion, days } 1 \text { and } 2+\text { FA } 200 \text {, continuous infusion, days } 1 \\
\text { and } 2 \text {, every } 2 \text { weeks (Lv5Fu } 2 \text { regimen) }\end{array}$ \\
\hline Giacchetti et al., $2000^{11}$ & $\begin{array}{l}\text { Oxaliplatin } 125 \text {, 6-hour infusion, day } 1+5 \text {-Fu } 700+\text { FA } 300 \text {, CM infusion; days } 1-5 \text {; every } 3 \text { weeks } \\
\text { versus } 5 \text {-Fu } 700+\text { FA } 300 \text {, CM infusion, days } 1-5 \text {, every } 3 \text { weeks }\end{array}$ \\
\hline \multirow[t]{2}{*}{$\begin{array}{l}\text { Giacchetti et al., } 2002^{12} \\
\text { (EORTC trial) }\end{array}$} & $\begin{array}{l}\text { Oxaliplatin 25, CM infusion (peak at 16:00), 5-Fu 750, CM infusion (peak at 04:00), FA 300, CM } \\
\text { infusion (peak at 04:00); all three drugs given daily for } 4 \text { days and repeated every } 2 \text { weeks versus }\end{array}$ \\
\hline & $\begin{array}{l}\text { Oxaliplatin 100, 2-hour infusion, day } 1 ; 5 \text {-Fu } 1500,22 \text {-hour infusion, daily for } 2 \text { days; FA } 600 \text {, } \\
\text { 2-hour infusion daily for } 2 \text { days; repeat every } 2 \text { weeks (FOLFOX } 2 \text { ) }\end{array}$ \\
\hline \multirow[t]{2}{*}{ Grothey et al., 2002, Germany ${ }^{13}$} & $\begin{array}{l}\text { Oxaliplatin } 50,2 \text {-hour infusion }+5 \text {-Fu } 2000,24 \text {-hour infusion }+ \text { FA } 500,24 \text {-hour infusion; days } 1,8 \text {, } \\
15 \text {, and } 22 \text {; every } 5 \text { weeks (FUFOX) versus }\end{array}$ \\
\hline & 5-Fu 425 bolus + FA 20, days $1-5$, every 29 days (Mayo) \\
\hline \multirow[t]{2}{*}{$\begin{array}{l}\text { Colucci et al., } 2003^{14} \\
\text { (GOIM trial) }\end{array}$} & $\begin{array}{l}\text { Oxaliplatin } 85 \text {, day } 1 \text {; FA 100, 2-hour infusion, days } 1 \text { and } 2 ; 5 \text {-Fu } 400 \text { bolus, followed by } 5 \text {-Fu } 600 \text {, } \\
22 \text {-hour infusion, days } 1 \text { and } 2 \text {; every } 2 \text { weeks versus }\end{array}$ \\
\hline & $\begin{array}{l}\text { Irinotecan 180, day 1; FA 100, 2-hour infusion, days } 1 \text { and 2; 5-FU } 400 \text { bolus, followed by } 5 \text {-Fu } 600 \text {, } \\
22 \text {-hour infusion, days } 1 \text { and } 2 \text {; every } 2 \text { weeks }\end{array}$ \\
\hline \multirow[t]{3}{*}{$\begin{array}{l}\text { Goldberg et al., } 2004^{15} \\
\text { (Intergroup N9741 trial) }\end{array}$} & $\begin{array}{l}\text { Oxaliplatin 85, day } 1 \text {, followed by } 5 \text {-Fu } 400 \text { bolus }+600 \text { 22-hour infusion, days } 1 \text { and 2; FA 200, } \\
\text { days } 1 \text { and 2; every } 2 \text { weeks (de Gramont FoLFox } 4 \text { ) versus }\end{array}$ \\
\hline & Irinotecan $125+5$-Fu $500+$ FA 20 ; days $1,8,15$, and 22 ; every 6 weeks (Saltz IFL) versus \\
\hline & Oxaliplatin 85 , day $1+$ irinotecan 200 , day 1 ; every 3 weeks (Wasserman IRox) \\
\hline $\begin{array}{l}\text { Tournigand et al., } 2004^{16} \\
\text { (GERCOR trial) }\end{array}$ & $\begin{array}{l}\text { First-line FOLFIRI: irinotecan } 180 \text { 2-hour infusion, day 1; FA } 200 \text { 2-hour infusion, day 1; 5-Fu } 400 \\
\text { bolus, day 1; followed by 5-Fu } 2400-300048 \text {-hour infusion, day } 2 \text {; every } 2 \text { weeks until progression, } \\
\text { then follow with second-line FOLFOX6 (as below) versus }\end{array}$ \\
\hline
\end{tabular}

continued 
JONKER et al.

APPENDIX B (continued)

\begin{tabular}{|c|c|}
\hline \multirow[t]{2}{*}{ Reference } & \multirow{2}{*}{$\begin{array}{l}\text { Regimen ( } \mathrm{mg} / \mathrm{m}^{2} \text { daily, frequency) } \\
\text { First-line FOLFOx6: oxaliplatin } 100 \text { 2-hour infusion, day 1; FA } 2002 \text {-hour infusion, day } 1 \text {; 5-Fu } 400 \\
\text { bolus, day } 1 \text {; followed by 5-FU } 2400-300048 \text {-hour infusion, day } 2 \text {; every } 2 \text { weeks until progression, } \\
\text { then follow with second-line FOLFIRI (as above) }\end{array}$} \\
\hline & \\
\hline $\begin{array}{l}\text { Comella et al., } 2005^{31} \\
\text { (SICOG) }\end{array}$ & $\begin{array}{l}\text { IRIFAFU: irinotecan } 200 \text { intravenously, day } 1 \text {; FA } 250 \text { intravenously, followed by } 5 \text {-FU } 850 \text {, day } 2 \\
\text { versus High-dose OXAFAFU: oxaliplatin } 100 \text {, day } 1 \text {; followed by FA } 250 \text { and } 5 \text {-Fu } 1050 \text {, day } 2 \text { versus } \\
\text { Low-dose OXAFAFU: oxaliplatin } 85 \text {, day } 1 \text {; FA } 250 \text { and } 5 \text {-FU } 850 \text {, day } 1\end{array}$ \\
\hline \multirow[t]{2}{*}{$\begin{array}{l}\text { Colucci et al., } 2005^{32} \\
\text { (GOIM) }\end{array}$} & $\begin{array}{l}\text { FOLFIRI: irinotecan 180, day 1; FA } 100 \text { 2-hour infusion, 5-Fu } 400 \text { bolus, followed by 5-Fu } 600 \text { 22-hour } \\
\text { infusion, days } 1 \text { and } 2 \text { versus }\end{array}$ \\
\hline & $\begin{array}{l}\text { FOLFOX 4: oxaliplatin 85, day 1; irinotecan 180, day 1; FA } 100 \text { 2-hour infusion, 5-Fu } 400 \text { bolus, } \\
\text { followed by 5-Fu } 600 \text { 22-hour infusion, days } 1 \text { and } 2\end{array}$ \\
\hline \multirow[t]{3}{*}{$\begin{array}{l}\text { Falcone et al., } 2006^{33} \\
\text { (GONO) }\end{array}$} & $\begin{array}{l}\text { FOLFOXIRI: oxaliplatin } 85 \text {, day } 1 \text {; irinotecan } 165 \text {, day } 1 ; 5 \text {-FU } 320048 \text {-hour infusion starting on day } 1 \text {; } \\
\text { l-FA } 200 \text {, day } 1 \text {; every } 2 \text { weeks versus }\end{array}$ \\
\hline & $\begin{array}{l}\text { FOLFIRI: irinotecan 180, day 1; 1-LV 100, days } 1 \text { and 2; 5-Fu } 400 \text { bolus, days } 1 \text { and 2; followed by } \\
5 \text {-Fu } 600 \text { 22-hour infusion, days } 1 \text { and } 2 \text {; every } 2 \text { weeks }\end{array}$ \\
\hline & At progression on FOLFIRI, a FOLFOX regimen was recommended \\
\hline Hospers et al., $2006^{34}$ & $\begin{array}{l}\text { OXAFAFU: oxaliplatin } 852 \text {-hour infusion, FA } 2001 \text {-hour infusion, } 5 \text {-Fu } 260024 \text {-hour infusion, day } 1 \text {, } \\
\text { every } 2 \text { weeks versusfaFU: } 5 \text {-Fu } 425 \text {, days } 1-5 \text {; FA } 20 \text {, days } 1 \text {-5; every } 4 \text { weeks }\end{array}$ \\
\hline \multirow[t]{2}{*}{$\begin{array}{l}\text { Souglakos et al., } 2006^{35} \\
\text { (HORG) }\end{array}$} & $\begin{array}{l}\text { FOLFOXIRI: oxaliplatin 65, day 2; irinotecan 150, day 1; FA 200, days } 2 \text { and } 3 ; 5 \text {-Fu } 400 \text { bolus, } \\
\text { followed by 5-Fu } 600 \text { 22-hour infusion, days } 2 \text { and } 3 \text { versus }\end{array}$ \\
\hline & $\begin{array}{l}\text { FOLFIRI: irinotecan 180, day 1; FA 200, days } 2 \text { and 3; 5-FU } 400 \text { bolus, followed by 5-Fu } 600 \text { 22-hour } \\
\text { infusion, days } 2 \text { and } 3\end{array}$ \\
\hline \multirow[t]{3}{*}{ Stanculeanu et al., $2006^{36}$} & $\begin{array}{l}\text { FOLFOX4: oxaliplatin } 85 \text {, day } 1 \text {; FA 200, days } 1 \text { and 2; 5-Fu } 400 \text { bolus, followed by } 5 \text {-Fu } 600 \text { 22-hour } \\
\text { infusion, days } 1 \text { and } 2 \text {; every } 15 \text { days versus }\end{array}$ \\
\hline & $\begin{array}{l}\text { FOLFIRI: irinotecan 180, FA 400, 5-FU } 400 \text { bolus, followed by 5-FU } 2400 \text { 46-hour infusion, every } \\
15 \text { days versus }\end{array}$ \\
\hline & IROX: irinotecan 300 , day 1 ; oxaliplatin 85 , day 2 ; every 3 weeks \\
\hline \multirow[t]{3}{*}{$\begin{array}{l}\text { Tournigand et al., } 2006^{37} \\
\text { (GERCOR) }\end{array}$} & $\begin{array}{l}\text { FOLFOX } 4: \text { oxaliplatin } 852 \text {-hour infusion, day } 1 \text {; FA } 2 \text {-hour infusion (either } 1001 \text {-LV or } 200 \mathrm{dl} \text {-LV), } \\
5 \text {-Fu } 400 \text { bolus, followed by 5-Fu } 60022 \text {-hour infusion, days } 1 \text { and } 2 \text {; every } 2 \text { weeks versus } \\
\text { FOLFOX } 7 \text { ( } 6 \text { cycles }) \rightarrow \text { LV5FU } 2 \text { ( } 12 \text { cycles }) \rightarrow \text { FOLFOX } 7 \text { ( } 6 \text { cycles) }\end{array}$ \\
\hline & $\begin{array}{l}\text { FOLFOX7: oxaliplatin } 130 \text { 2-hour infusion, day 1; FA 2-hour infusion (either 1-LV } 200 \text { or dl-Lv 400), } \\
\text { followed by 5-Fu } 2400 \text { 46-hour infusion; every } 2 \text { weeks }\end{array}$ \\
\hline & $\begin{array}{l}\text { LV5FU2: FA 2-hour infusion (either l-Lv } 200 \text { or dl-Lv 400), 5-Fu } 400 \text { bolus, followed by 5-Fu } 3000 \\
\text { 46-hour infusion, every } 2 \text { weeks }\end{array}$ \\
\hline \multicolumn{2}{|l|}{ Second-line treatment } \\
\hline \multirow{3}{*}{$\begin{array}{l}\text { Rothenberg et al., } 2003^{30} \\
\text { (EFC4584 trial) }\end{array}$} & Treatment given as second-line to IFL \\
\hline & $\begin{array}{l}\text { Oxaliplatin } 85 \text { 2-hour infusion, day 1; 5-Fu } 400 \text { bolus, followed by 5-Fu } 600 \text { 22-hour infusion, } \\
\text { days } 1 \text { and 2; every } 2 \text { weeks (FolFox4) versus }\end{array}$ \\
\hline & $\begin{array}{l}\text { 5-FU } 400 \text { bolus, followed by } 5 \text {-Fu } 600 \text { 22-hour infusion, days } 1 \text { and 2; FA 200; every } 2 \text { weeks } \\
\text { (LV5Fu2) }\end{array}$ \\
\hline \multirow{4}{*}{$\begin{array}{l}\text { Garay et al., } 2003^{17} \\
\text { (Sanofi/Memorial Sloan Kettering }\end{array}$} & Treatment given as second-line to 5-Fu + irinotecan \pm FA \\
\hline & Cancer Centre crossover trial) Oxaliplatin 85 2-hour infusion, day 1; 5-FU 400 bolus; followed by \\
\hline & 5-Fu 600 22-hour infusion, days 1 and 2; every 2 weeks (FOLFOX4) versus \\
\hline & $\begin{array}{l}\text { 5-FU } 400 \text { bolus, followed by 5-Fu } 600 \text { 22-hour infusion, days } 1 \text { and 2; FA 200; every } 2 \text { weeks } \\
\text { (LV5FU2) }\end{array}$ \\
\hline \multirow[t]{6}{*}{$\begin{array}{l}\text { Giantonio et al., } 2005^{38} \\
\text { (ECOG) }\end{array}$} & $\begin{array}{l}\text { FOLFOX } 4 \text { + bevacizumab: bevacizumab } 10 \mathrm{mg} / \mathrm{kg} \text { intravenously, biweekly; oxaliplatin } 85 \text {, day } 1 \text {; } \\
\text { FA } 2002 \text {-hour infusion, } 5 \text {-Fu } 400 \text { bolus, followed by } 5 \text {-Fu } 60022 \text {-hour infusion, days } 1 \text { and } 2 \text { versus } \\
\text { FOLFOx } 4 \text { : oxaliplatin } 85 \text {, day } 1 \text {; FA } 2002 \text {-hour infusion } 5 \text {-Fu } 400 \text { bolus, followed by } 5 \text {-Fu } 600\end{array}$ \\
\hline & $\begin{array}{l}\text { FOLFOX4: oxalıplatın 85, day 1; FA } 2002 \\
22 \text {-hour infusion, days } 1 \text { and } 2 \text { versus }\end{array}$ \\
\hline & Bevacizumab: bevacizumab $10 \mathrm{mg} / \mathrm{kg}$ intravenously, biweekly \\
\hline & Irinotecan $\rightarrow$ FOLFOX 4 versus FOLFOX $4 \rightarrow$ irinotecan \\
\hline & $\begin{array}{l}\text { Irinotecan } 350 \text {, day } 1 \text {, every } 3 \text { weeks (reduced to } 300 \text { for ECOG performance status } 2 \text {, age } \geq 70 \text {, or } \\
\text { prior pelvic radiation) }\end{array}$ \\
\hline & $\begin{array}{l}\text { FOLFOX4: oxaliplatin 85, FA 200, 5-Fu } 400 \text { bolus, followed by } 600 \text { 22-hour infusion, days } 1 \text { and 2, } \\
\text { every } 2 \text { weeks }\end{array}$ \\
\hline
\end{tabular}

IOCC = International Organization Against Cancer; 5-FU = 5-fluorouracil; FA = folinic acid; $\mathrm{CM}=$ chronomodulated; EORTC = European Organization for Research and Treatment of Cancer; GOIM = Gruppo Oncologico Italia Meridionale; GERCOR = Groupe Coopérateur Multidisciplinaire en Oncologie; SICOG = Southern Italy Cooperative Oncology Group; 1-FA = levo-folinic acid; GONO = Gruppo Oncologico Nord Ovest; 1-LV = levo-leucovorin calcium; HORG = Hellenic Oncology Research Group; dl-LV = racemic leucovorin calcium; ECOG = Eastern Cooperative Oncology Group. 